\title{
Pengaruh Citra Merek dan Kualitas Pelayanan terhadap Kepuasan Pelanggan Restoran Mangkok Ku
}

\author{
Charlie Giovani Gunardi, Rezi Erdiansyah \\ charliegiovanigunardi@gmail.com; rezie@fikom.untar.ac.id \\ Fakultas Ilmu Komunikasi Universitas Tarumanagara
}

\begin{abstract}
This study aims to determine the effect of brand image and service quality on customer satisfaction at Mangkok Ku. Research using quantitative methods. The number of samples from this study were 145 respondents taken using nonrandom sampling data collection techniques, by filling out a questionnaire on Google Form. The analysis technique is done by SEM through the Lisrel 8.70 program. The results showed that brand image did not significantly influence customer satisfaction, while service quality significantly affected customer satisfaction. Thus, to improve customer satisfaction, an increase in service quality at Mangkok Ku is needed.
\end{abstract}

Keywords: brand image, customer satisfaction, mangkok ku, service quality.

\begin{abstract}
Abstrak
Penelitian ini bertujuan untuk mengetahui pengaruh citra merek dan kualitas pelayanan terhadap kepuasan pelanggan restoran Mangkok Ku. Penelitian menggunakan metode kuantitatif. Jumlah sampel dari penelitian ini sebanyak 145 responden yang diambil dengan menggunakan teknik pengumpulan data non random sampling, dengan cara pengisian kuesioner pada google form. Teknik analisis dilakukan dengan SEM melalui program Lisrel 8.70. Hasil penelitian menunjukkan bahwa citra merek tidak berpengaruh secara signifikan terhadap kepuasan pelanggan, sedangkan kualitas layanan berpengaruh secara signifikan terhadap kepuasan pelanggan. Dengan demikian, untuk meningkatkan kepuasan pelanggan diperlukan peningkatan pada kualitas pelayanan pada restoran Mangkok Ku.
\end{abstract}

Kata Kunci: Citra Merek, Kualitas Pelayanan, Kepuasan Pelanggan, Restoran Mangkok Ku

\section{Pendahuluan}

Pada saat ini industri makanan merupakan industri yang paling diminati karena mudah untuk dibuat dan memiliki presentase keuntungan yang baik kedepannya. Namun kondisi persaingan yang semakin tinggi antar perusahaan, menyebabkan setiap perusahaan saling berlomba-lomba untuk memasarkan perusahaannya. Harapan dari adanya perluasan pasar secara langsung adalah perusahaan akan memiliki lebih banyak pelanggan sehingga pada akhirnya penjualan akan meningkat. Terdapat hal yang harus dipahami perusahaan pelaku bisnis, selaku produsen, yaitu memberikan kepuasan kepada pelanggan dengan memenuhi keinginan dan harapan dari pelanggan dan menjaga kualitas merek agar tertanam kuat dalam persepsi konsumen secara positif.

Menurut Kotler dan Keller (dalam Tangguh, 2018), kepuasan pelanggan adalah tingkat perasaan yang timbul setelah membandingkan kinerja yang diperoleh ataupun dirasakan oleh pelanggan, sementara itu menurut Kotler dan Keller (dalam Tangguh, 2018) "Merek adalah nama, istilah, tanda, lambang, atau desain atau kombinasinya untuk mengidentifikasikan barang atau jasa dari salah satu penjual atau kelompok 
penjual dan mendiferensiasikan mereka dari para pesaing". Sementara itu citra merek didefinisikan sebagai pandangan atau penilaian oleh setiap individu tentang suatu produk atau merek.

Ferrinadewi (2008) mengatakan bahwa citra terhadap suatu produk sangat melekat dan tidak dapat dipisahkan dari merek dan perusahaan pemilik produk tersebut. Citra Merek berhubungan dengan sikap tentang keyakinan terhadap suatu merek dan membantu mempresentasikan persepsi dari informasi terhadap merek itu sendiri. Hal ini dibuktikan dalam penelitian Ridho (2017) yang menyatakan bahwa citra merek suatu perusahaan berpengaruh terhadap tingkat kepuasan pelanggan.

Aspek lain yang perlu diperhatikan yaitu kualitas pelayanan karena menurut Cronin dan Taylor (dalam Sondakh, 2014), kualitas pelayanan merupakan faktor utama dalam kepuasan pelanggan, dimana pelanggan menilai kinerja pelayanan yang diterima dan yang dirasakan langsung terhadap suatu produk. Kualitas pelayanan ditentukan oleh bagaimana tingkat kesesuaian antara pelayanan yang diberikan dengan harapan yang diharapkan oleh pengguna layanan. Selain itu menurut Tjiptono (dalam Prasetio,2012) mengungkapkan bahwa kualitas memiliki hubungan yang erat dengan kepuasan pelanggan. Perusahaan yang tingkat kepuasan pelanggannya tinggi menyediakan tingkat layanan pelanggan yang tinggi pula.

Semakin tinggi kualitas pelayanan yang dirasakan akan semakin tinggi tingkat kepuasan pengguna/pelanggan, selanjutnya akan berdampak positif pada perilaku ataupun niat seseorang dalam menyikapi pelayanan tersebut. Menurut Kotler dan Keller (dalam Tangguh 2018), mengatakan bahwa bila kualitas layanan suatu jasa baik, maka pelanggan akan puas, tetapi bila sebaliknya kualitas layanan yang tidak sesuai dengan harapan, pelanggan tidak akan puas dan mempengaruhi sikap pelanggan pada masa mendatang.

Diantara banyaknya restoran yang terdapat di Jakarta, Mangkok Ku merupakan salah satu restoran yang memiliki keunikan sendiri dan berbeda dari restoran lainnya, Mangkok Ku merupakan salah satu restoran hits karena para pendirinya, yang terdiri dari kolaborasi Gibran Rakabuming, Kaesang Pangarep, dan chef Arnold, serta Randy Julius. Restoran yang memadukan kuliner khas Jepang dan Nusantara ini berlokasi di kawasan Tanjung Duren, Jakarta Barat.

Dengan memiliki pendiri yang sudah dikenal masyarakat, maka penulis ingin meneliti bagaimana pengaruh citra merek yang dimiliki oleh Mangkok Ku karena para pendirinya yang sudah terlebih dahulu memiliki citra yang bagus di mata masyarakat apakah dapat mempengaruhi citra merek Mangkok Ku terhadap kepuasan pelanggan, serta penulis juga tertarik dengan kualitas pelayanan yang diberikan oleh Mangkok $\mathrm{Ku}$. Berdasarkan uraian diatas maka peneliti melakukan penelitian yang berkaitan dengan citra merek dan kualitas pelayanan yang mempengaruhi kepuasan pelanggan sehingga penelitian ini diberi judul "Pengaruh Citra Merek terhadap Kepuasan Pelanggan Restoran Mangkok Ku”.

\section{Citra Merek}

Menurut Kotler dan Keller (dalam Santoso, 2019), citra merek adalah kombinasi dari keseluruhan (nama, istilah, simbol, rancangan dan lain-lain) yang ditujukan untuk mengenali barang atau jasa penjual sehingga berbeda dengan barang atau jasa yang dimiliki oleh pesaing. Persepsi pelanggan merupakan hasil pemikiran dan penilaian konsumen berdasar penginderaan dari objek-objek fisik maupun sosial tergantung pada stimulus di lingkungannya. 


\section{Kualitas Pelayanan}

Menurut Tjiptono (dalam Tangguh, 2018) menyatakan bahwa pada prinsipnya, kualitas jasa yaitu sebuah upaya untuk berfokus pada pemenuhan harapan, keinginan dan kebutuhan konsumen agar dapat tersampaikan secara tepat dan benar. Menurut kotler dan keller (dalam Apriyani, 2013) pelayanan/jasa (service) adalah sebuah tindakan atau kinerja yang dapat ditawarkan satu pihak kepada pihak lain yang pada intinya tidak berwujud dan tidak menghasilkan kepemilikan apapun. Sedangkan menurut Gronroos (dalam Insu et.al, 2010) kualitas pelayanan didefinisikan sebagai hasil dari proses evaluasi dimana konsumen membandingkan harapan mereka atas layanan tertentu yang mereka terima. Prasuraman, Zathaml, dan Berry (dalam Isnu et.al, 2010) mengatakan bahwa kualitas pelayanan dilihat sebagai kesenjangan antara konsumen dan persepsi mereka terhadap layanan yang sebenarnya.

\section{Kepuasan Pelanggan}

Kepuasan pelanggan merupakan suatu tingkatan dimana kebutuhan, keinginan dan harapan dari pelanggan terpenuhi yang akan mengakibatkan terjadinya pembelian ulang atau kesetiaan pelanggan yang berlanjut (Musanto, 2004).

Selain menurut Zeithaml and Bitner (dalam jurnal Tangguh, 2018) definisi kepuasan adalah tanggapan konsumen terhadap suatu produk atau jasa apakah telah memenuhi kebutuhan dan ekspektasi pelanggan. Kepuasan merupakan penilaian mengenai ciri atau keistimewaan produk atau jasa, atau produk itu sendiri, yang menyediakan tingkat kesenangan konsumen berkaitan dengan pemenuhan kebutuhan konsumsi konsumen.

\section{Hipotesis}

$\mathrm{H}_{1}$ : Citra Merek memiliki pengaruh yang signifikan terhadap kepuasan pelanggan

$\mathrm{H}_{2}$ : Kualitas Pelayanan memiliki pengaruh yang signifikan terhadap kepuasan pelanggan.

$\mathrm{H}_{3}$ : Citra Merek dan Kualitas Pelayanan memiliki pengaruh signifikan terhadap Kepuasan Pelanggan.

\section{Metode Penelitian}

Terdapat enam indikator dalam membentuk dimensi variabel Citra Merek (Keller 2003), terdapat tiga belas indikator yang membentuk dimensi variabel Kualitas Pelayanan menurut Zeithaml et. Al (dalam Apriyani, 2013), dan yang terakhir terdapat sembilan indikator yang membentuk dimensi Kepuasan Pelanggan menurut Hawkins dan Lonney (dalam Tjiptono, 2004)

Menurut Sugiyono (2016) kuesioner merupakan teknik pengumpulan data yang dilakukan dengan cara memberi seperangkat pertanyaan atau pernyataan tertulis kepada responden untuk dijawab. Kuesioner dalam penelitian ini bersifat tertutup karena alternatif jawaban dalam kuesioner telah ditetapkan oleh peneliti (Noor, 2017:139). Instrumen yang digunakan dalam penelitian ini berupa skala yaitu tersedia pilihan jawaban berdasarkan tingkatan tertentu (Noor, 2017).

\section{Hasil Temuan dan Diskusi}

Jumlah keseluruhan responden dari penelitian ini sebanyak 145 responden. Jumlah responden berdasarkan jenis kelamin, jenis kelamin laki-laki sebanyak 76 
orang dengan persentase 52,4\% sedangkan responden jenis kelamin perempuan sebanyak 69 orang atau dengan persentase $47,6 \%$. Mayoritas responden penelitian ini berusia 21 tahun sampai 25 tahun yaitu sebanyak 110 orang dengan persentase sebesar $75,9 \%$. Yang kedua adalah responden yang berusia $\leq 20$ tahun sebanyak 24 orang dengan persentase $16,6 \%$. Yang ketiga adalah responden yang berusia $26-30$ tahun yaitu sebanyak 7 orang dengan presentase sebesar 4,8\%. Dan yang keempat dengan jumlah yang sama adalah responden yang berusia 31 tahun sampai 35 tahun juga responden yang berusia $\geq 36$ tahun yaitu sebanyak 7 orang dengan persentase $6,7 \%$. Berdasarkan tempat tinggal berdomisili di jakarta barat sebanyak 54 orang dengan presentase $37,2 \%$. Yang kedua adalah respoden yang berdomisili di jakarta utara sebanyak 27 orang dengan presentase 18,6\%. Ketiga adalah responden yang berdomisili di jakarta timur sebanyak 26 orang dengan presentase 17,9\%, yang keempat adalah responden yang berdomisili di Jakarta Pusat sebanyak 22 orang dengan presentase $15,2 \%$ dan yang terakhir adalah responden yang bertempat tinggal diluar jakarta dengan responden sebesar 16 orang dengan presentase sebesar $11 \%$.

\section{Model Pengukuran}

Uji validitas dalam penelitian ini dengan melihat nilai yang terdapat pada kolom corrected item total correlation yang dihitung dengan menggunakan program SPSS ver 15.0. Uji validitas adalah suatu alat ukur yang menunjukkan tingkat ke validan atau keabsahan suatu tes sebuah penelitian. Untuk menilai butir dalam kuisoner tersebut valid atau tidak adalah dengan menggunakan patokan 0,2 dibandingkan dengan angka pada kolom Corrected Item Total Correlation, jika angka yang terdapat berada dibawah 0,2 atau bertanda negatif (-) maka dinyatakan tidak valid (gugur), sebaliknya, bila angka korelasinya berada diatas 0,2 maka data dinyatakan valid (Nisfiannoor, 2013).

Tabel 1. Hasil Uji Validitas

\begin{tabular}{|c|c|c|c|}
\hline Variabel & Butir Indikator & $\begin{array}{l}\text { Corrected } \\
\text { Item Total } \\
\text { Correlation }\end{array}$ & Keterangan \\
\hline \multirow{6}{*}{ Citra Merek } & $\begin{array}{l}\text { Mangkok Ku sudah memberikan } \\
\text { informasi yang berguna }\end{array}$ & 0.562 & Valid \\
\hline & $\begin{array}{l}\text { Mudah memperoleh informasi dari } \\
\text { Mangkok Ku (Promo) }\end{array}$ & 0.449 & Valid \\
\hline & $\begin{array}{l}\text { Logo dari Mangkok Ku mudah untuk } \\
\text { diingat }\end{array}$ & 0.491 & Valid \\
\hline & $\begin{array}{l}\text { Saya percaya terhadap merek } \\
\text { Mangkok Ku }\end{array}$ & 0.512 & Valid \\
\hline & $\begin{array}{l}\text { Logo yang dimiliki Mangkok Ku } \\
\text { memiliki keunikan tersendiri }\end{array}$ & 0.509 & Valid \\
\hline & $\begin{array}{l}\text { Mangkok Ku memiliki keunikan } \\
\text { dalam mempromosikan mereknya }\end{array}$ & 0.492 & Valid \\
\hline \multirow[t]{3}{*}{$\begin{array}{l}\text { Kualitas } \\
\text { Pelayanan }\end{array}$} & $\begin{array}{l}\text { Fasilitas yang diberikan Mangkok Ku } \\
\text { bersih dan layak pakai }\end{array}$ & 0.282 & Valid \\
\hline & $\begin{array}{l}\text { Penampilan karyawan Mangkok Ku } \\
\text { rapi }\end{array}$ & 0.446 & Valid \\
\hline & $\begin{array}{l}\text { Fasilitas yang digunakan Mangkok Ku } \\
\text { memiliki design modern }\end{array}$ & 0.446 & Valid \\
\hline
\end{tabular}


Charlie Giovani Gunardi, Rezi Erdiansyah: Pengaruh Citra Merek dan Kualitas Pelayanan Terhadap Kepuasan Pelanggan Restoran Mangkok Ku

Mangkok Ku menyediakan jasa pelayanan yang baik dari awal datan hingga akhir

\begin{tabular}{lcc}
\hline $\begin{array}{l}\text { Mangkok Ku memberikan pelayanan } \\
\text { yang akurat dalam proses pembayaran }\end{array}$ & 0.529 & Valid \\
\hline $\begin{array}{l}\text { Mangkok Ku memberikan pelayanan } \\
\text { yang sesuai dengan yang dijanjikan }\end{array}$ & 0.543 & Valid \\
\hline $\begin{array}{l}\text { Karyawan Mangkok Ku memberikan } \\
\text { pelayanan dengan cepat }\end{array}$ & 0.572 & Valid \\
\hline
\end{tabular}

\begin{tabular}{lll}
\hline $\begin{array}{l}\text { Responden terbantu oleh karyawan } \\
\text { Mangkok Ku pada saat merasa } \\
\text { kesulitan }\end{array}$ & 0.552 & Valid \\
\hline $\begin{array}{l}\text { karyawan Mangkok Ku masih } \\
\text { memberikan pelayanan yang baik } \\
\text { meskipun sibuk }\end{array}$ & 0.619 & Valid \\
\hline $\begin{array}{l}\text { Karyawan Mangkok Ku memiliki } \\
\text { kemampuan yang baik dalam } \\
\text { pelayanan }\end{array}$ & 0.553 & Valid \\
\hline $\begin{array}{l}\text { Karyawan Mangkok Ku memberikan } \\
\text { layanan yang ramah }\end{array}$ & 0.536 & Valid \\
\hline $\begin{array}{l}\text { Karyawan Mangkok Ku memberikan } \\
\text { perhatian secara personal }\end{array}$ & 0.503 & Valid \\
\hline $\begin{array}{l}\text { Karyawan Mangkok Ku } \\
\text { memperhatikan kebutuhan pelanggan }\end{array}$ & 0.487 & Valid \\
$\begin{array}{l}\text { Makanan yang disediakan Mangkok } \\
\text { Ku sesuai harapan }\end{array}$ & 0.503 & Valid \\
\hline $\begin{array}{l}\text { Pelayanan yang diberikan karyawan } \\
\text { Mangkok Ku sesuai diharapkan }\end{array}$ & 0.522 & Valid \\
\hline $\begin{array}{l}\text { Fasilitas yang diberikan Mangkok Ku } \\
\text { sesuai yang diharapkan }\end{array}$ & 0.565 & Valid \\
\hline $\begin{array}{l}\text { Saya berminat untuk berkunjung } \\
\text { kembali, karena pelayanan yang } \\
\text { diberikan memuaskan }\end{array}$ & 0.574 & Valid \\
\hline $\begin{array}{l}\text { Saya berminat untuk berkunjung } \\
\text { kembali ke Mangkok Ku karena rasa } \\
\text { makanan yang ditawarkan sesuai } \\
\text { diharapkan }\end{array}$ & 0.595 & Valid \\
\hline $\begin{array}{l}\text { Saya bermat untuk berkunjung } \\
\text { arangara }\end{array}$ & & \\
\hline
\end{tabular}

Kepuasan Pelanggan

Saya berminat untuk berkunjung kembali ke Mangkok Ku karena fasilitas penunjang yang disediakan Valid memadai Saya menyarankan Mangkok Ku kepada teman atau kerabat karena 0.527 Valid pelayanan yang diberikan memuaskan

Saya menyarankan kepada teman untuk membeli makan di Mangkok Ku karena fasilitas yang disediakan Valid memadai

Saya menyarankan teman untuk membeli makanan Mangkok Ku, karena rasa makanan yang ditawarkan 
Reliabilitas adalah uji yang digunakan untuk mengetahui sejauh mana hasil pengukuran tetap konsisten, apabila dilakukan pengukuran lebih terhadap gejala yang sama dengan menggunakan alat pengukur yang sama (Siregar, 2013). Penelitian ini dihitung dengan rumus Cronbach's Alpha. Metode Cronbach's Alpha yang digunakan untuk menghitung reliabilitas suatu tes yang tidak memiliki pilihan "benar" atau "salah" melainkan digunakan untuk menghitung reliabilitas suatu tes yang mengukur sikap atau perilaku. Suatu instrument dikatakan reliabel apabila memiliki nilai Cronbach's Alpha lebih dari 0.6 (Siregar, 2012:175).

\begin{tabular}{l|c|c}
\multicolumn{4}{c}{ Tabel 2. Hasil Uji Reliabilitas } \\
Variabel & Nilai Cronbach's Alpha & Keterangan \\
\hline Citra Merek & 0,759 & Reliabel \\
\hline Kualitas Pelayanan & 0,849 & Reliabel \\
\hline Kepuasan Pelanggan & 0,852 & Reliabel \\
\hline
\end{tabular}

Sumber: Data Primer, diolah dengan SPSS 15

\begin{tabular}{cccccc}
\hline Hipotesis & Path & $\begin{array}{c}\text { Standardized } \\
\text { Solution }\end{array}$ & T Values & T Tabel & Keterangan \\
\hline $\mathrm{H}_{1}$ & $\begin{array}{c}\text { Citra Merek }\left(\mathrm{X}_{1}\right) \\
\text { Kepuasan Pelangan }(\mathrm{Y})\end{array}$ & 0.10 & 1.11 & 1.96 & Ditolak \\
\hline $\mathrm{H}_{2}$ & $\begin{array}{c}\text { Kualitas Pelayanan }\left(\mathrm{X}_{2}\right) \\
\text { Kepuasan Pelangtan (Y) }\end{array}$ & 0.76 & 3.30 & 1.96 & Diterima \\
\hline \multicolumn{1}{c}{$\begin{array}{c}\text { Citra Merek Kualitas } \\
\mathrm{H}_{3}\end{array}$} & $\begin{array}{c}\text { Pelayanan (X1 dan X2) } \\
\text { Kepuasan Pelłnggan } \\
(\mathrm{Y})\end{array}$ & 0.86 & 21.28 & 1.96 & Diterima \\
\hline
\end{tabular}

Tabel 3 Hasil Pengujian Hipotesis

Sumber: Data diolah dengan Lisrel 8.70

\section{Diskusi}

Pada hipotesis $1, \mathrm{H}_{1}$ ditolak yang artinya tidak terdapat pengaruh positif dan signifikan dari Citra Merek terhadap Kepuasan Pelanggan. Hipotesis penelitian ini sependapat dengan penelitian yang dilakukan oleh Tangguh dkk (2018), dengan judul pengaruh citra merek, kualitas layanan, dan harga terhadap kepuasan pelanggan GORIDE (Survei pada Mahasiswa Fakultas Ilmu Administrasi Universitas Brawijaya Angkatan 2016/2017 dan 2017/2018). Hasil penelitian ini tidak mendukung pernyataan yang dikemukakan oleh Kotler. Menurut Kotler (2007) Citra merek (brand image) adalah nama, istilah, tanda, simbol, desain khusus, atau kombinasi dari unsurunsur tersebut yang berfungsi untuk mengidentifikasi produk perusahaan yang tidak hanya membedakannya dari produk pesaing namun merupakan janji produsen atau kontrak. Kepercayaan dari produsen kepada konsumen dengan menjamin konsistensi bahwa sebuah produk akan selalu dapat menyampaikan nilai yang diharapkan konsumen dari sebuah produk.

Pada hipotesis 2, diterima yang artinya terdapat pengaruh positif dan signifikan dari Kualitas Pelayanan terhadap Kepuasan Pelanggan. Dengan demikian semakin tinggi kualitas pelayanan maka akan semakin meningkatkan Kepuasan Pelanggan Restoran Mangkok Ku. Hipotesis pada penelitian ini didukung oleh penelitian terdahulu yang dilakukan oleh Nabila (2017), dengan judul Pengaruh Promosi dan Kualitas Pelayanan belanja online terhadap Kepuasan Konsumen Traveloka. 
Pada hipotesis $3, \mathrm{H}_{3}$ diterima yang artinya tidak terdapat pengaruh dari Citra Merek dan Kualitas Pelayanan terhadap Kepuasan Pelanggan. Dengan demikian semakin tinggi Citra Merek dan Kualitas Pelayanan maka tidak akan meningkatkan Kepuasan Pelanggan. Hal ini sependapat dengan penelitian yang dilakukan oleh Tombokan dkk (2015), dengan judul pengaruh kualitas pelayanan, citra merek terhadap kepuasan konsumen pengguna taplus BNI kantor cabang utama Manado.

\section{Kesimpulan}

Berdasarkan hasil dari pembahasan dan hasil penelitian pada pembahasan di bab sebelumnya, maka didapatkan kesimpulan dari penelitian ini adalah sebagai berikut:

1. Citra merek tidak berpengaruh positif dan signifikan terhadap Kepuasan Pelanggan.

2. Kualitas pelayanan berpengaruh positif dan signifikan terhadap Kepuasan Pelanggan.

3. Citra merek dan variabel kualitas pelayanan tidak berpengaruh positif dan signifikan terhadap Kepuasan Pelanggan.

\section{Ucapan Terima Kasih}

Terima kasih kepada Tuhan yang Maha Esa dan kepada teman-teman peneliti yang selalu membantu saya dalam proses menyelesaikan jurnal ini.

\section{Daftar Pustaka}

Apriyani (2013). Pengaruh brand image, Harga Dan Kualitas Pelayanan Terhadap Keputusan Pembelian Ulang Pizza Hut Di Kota Padang. Jurnal Manajemen 2.01

Efendy, Audya, Suryadinata (2015). Analisa Pengaruh Brand Image dan Brand Trust terhadap Brand Loyalty di restoran D'cost Surabaya. Jurnal Manajemen Perhotelan, Universitas Kristen Petra, Surabaya, Indonesia

Ferrinadewi, Erna. (2008). Merek \& Psikologi Konsumen: Implikasi pada Strategi Pemasaran. Yogyakarta: Graha Ilmu.

Insu Park, Amit Bhatnagar \& H. Raghav Rao. 2010. "Assurance Seals, On-Line Customer Satisfaction, and Repurchase Intention”. International Journal of Electronic Commerce / Spring Vol. 14 No.3).11-34.

Keller, Kevin Lane. (2003). Strategic Brand Management: Building, Measuring, and Managing Brand Equity. New Jersey: Prentice Hall.

Kotler, Philip dan Kevin Lane Keller. (2007). Manajemen Pemasaran. Edisi Kedua Belas Jilid 1. Jakarta: Indeks.

Musanto (2004). Faktor-Faktor Kepuasan Pelanggan dan Loyalitas Pelanggan: Studi Kasus pada CV. Sarana Media Advertising Surabaya. Jurnal Manajemen \& Kewirausahaan Vol. 6, No. 2, September 2004: 123 - 136.

Nabila Zahrah Azka. (2017). Pengaruh Promosi dan Kualitas Pelayanan Dalam Belanja Online Terhadap Kepuasan Konsumen Traveloka. Jurnal magister ilmu komunikasi program pascasarjana Universitas Pasundan Bandung.

Nisfiannoor (2013). Pendekatan Statistika Modern Aplikasi dengan software SPSS dan E-Views. Jakarta. Usakti. 
Noor Nuruzzaman Andreas Kafizas, Yimeng Ma, Ernest Pastor, Stephanie R. Pendlebury, Camilo Mesa, Laia Francàs, Florian Le Formal, Min Ling, Carlos Sotelo-Vazquez, Claire J. Carmalt, Ivan P. Parkin, and James R. Durrant. (2017). Water Oxidation Kinetics of Accumulated Holes on the Surface of a TiO2 Photoanode: A Rate Law Analysis. ACS Catalysis 2017.

Prasetio Ari. (2012). Pengaruh Kualitas pelayanan dan Harga Terhadap Kepuasan Pelanggan. Artikel Publikasi, Fakultas Ekonomi, Universitas Negeri Semarang, Indonesia.

Rangkuti, Freddy. (2004). Manajemen Persediaan Aplikasi di Bidang Bisnis. Jakarta: PT. Raja Grafindo Persada.

Ridho, Suharyono (2017). Pengaruh kualitas Produk Terhadap pada Brand Image dan Dampaknya Pada Kepuasan Pelanggan (Survei pada Pelanggan kartu prabayar Simpati, Kota Malang). Jurnal Administrasi Bisnis (JAB)|Vol. 53 No. 1 Desember 2017.

Santoso, D. A., Erdiansyah, R., \& Pribadi, M. A. (n.d.). Pengaruh Brand Awareness dan Brand Image terhadap Minat Beli Produk Kecantikan Innisfree, 286-290.

Siregar, Syofian. (2012). Metode Penelitian Kuantitatif Dilengkapi Dengan Perbandingan Perhitungan Manual dan SPSS. Jakarta: Prenada media Group

Siregar, Syofian. (2013). Metode Penelitian Kuantitatif. Jakarta. PT Fajar Interpratama Mandiri.

Sondakh (2014). Kualitas Layanan, Citra Merek Dan Pengaruhnya Terhadap Kepuasan Nasabah Dan Loyalitas Nasabah Tabungan (Studi Pada Nasabah Taplus BNI Cabang Manado). Jurnal Riset Bisnis dan Manajemen Vol.3, No.1, 2014:19-32.

Sugiyono. (2016). Metode Penelitian Kuantitatif, Kualitatif dan $R \& D$. Bandung: PT Alfabet.

Suwadni, Sularso, Suroso. (2015). Pengaruh Kualitas Layanan, Harga, dan Citra Merek terhadap Kepuasan dan Loyalitas Pelanggan Pos Ekspres di kantor Bondowoso dan Situbondo. Jurnal JEAM Vol XIV April 2015.

Tangguh, Pangestuti, Perwangsa. (2018). Pengaruh Citra Merek, Kualitas Layanan, dan Harga Terhadap Kepuasan Pelanggan GO-RIDE (Survei pada Mahasiswa Fakultas Ilmu Administrasi Universitas Brawijaya Angkatan 2016/2017 dan 2017/2018). Jurnal Administrasi Bisnis (JAB)|Vol. 61 No. 2

Tjiptono, Fandy. (2007).” Manajemen Jasa", Andy Offset, Yogyakarta.

Tjiptono, Fandy. 2004. Manajemen Jasa, Edisi Pertama, Yogyakarta, Andi Offset.

Tombokan, Kawer, Uhing. (2015). Pengaruh Kualitas Pelayanan, Citra Merek terhadap Kepuasan Konsumen pengguna Taplus BNI Kantor Cabang Utama Manado.Jurnal EMBA Vol.3 No.3 Sept. 2015, Hal.552-561 